\title{
Stressful Events and Individual Beliefs as Correlates of Economic Disadvantage and Aggression Among Urban Children
}

\author{
Nancy G. Guerra \\ University of Illinois at Chicago \\ and University of Michigan \\ Patrick H. Tolan \\ University of Illinois at Chicago
}

\author{
L. Rowell Huesmann \\ University of Michigan
}

\author{
Richard Van Acker \\ University of Illinois at Chicago
}

\author{
Leonard D. Eron \\ University of Michigan
}

\begin{abstract}
This study examined 3 factors that were hypothesized to increase risk for aggression among urban children: economic disadvantage, stressful events, and individual beliefs. Participants were 1,935 African American, Hispanic, and White elementary-school boys and girls assessed over a 2-year period. The relation between individual poverty and aggression was only significant for the White children, with significant interactions between individual and community poverty for the other 2 ethnic groups. With a linear structural model to predict aggression from the stress and beliefs variables, individual poverty predicted stress for African American children and predicted beliefs supporting aggression for Hispanic children. For all ethnic groups, both stress and beliefs contributed significantly to the synchronous prediction of aggression, and for the Hispanic children, the longitudinal predictions were also significant. The findings are discussed in terms of their implications for preventive interventions in multiethnic, inner-city communities.
\end{abstract}

Violent crime rates in the United States in the early 1990s are the highest in several decades. This latest upswing is largely accounted for by a sharp increase in violence among youths under age 18. For example, during the 1980s, arrests for serious violent crimes rose about $5 \%$ for those over 18 , compared with a $60 \%$ rise for those under age 18 (Uniform Crime Reports, 1992). This escalation has placed violence prevention at the forefront of scientific and public concern, leading to a proliferation of interventions for children and youths (for recent reviews see Guerra, Tolan, \& Hammond, 1994; Kazdin, 1987, 1994; Tolan \& Guerra, in press; Yoshikawa, 1994; Zigler, Taussig, \& Black, 1992).

In developing preventive interventions, it is important to identify populations most at-risk for violent behavior and to understand the precursors of serious violent criminal behavior

Nancy G. Guerra, Department of Psychology, University of Illinois at Chicago, and Department of Psychology, University of Michigan; L. Rowell Huesmann and Leonard D. Eron, Department of Psychology, University of Michigan; Patrick H. Tolan and Richard Van Acker, Department of Psychology, University of Illinois at Chicago.

This research was supported by Grant MH- 48034 from the National Institute of Mental Health and Cooperative Agreement CCU510017 from the Centers for Disease Control and Prevention.

We thank David Henry and Ed Czilli for their assistance with data analysis.

Correspondence concerning this article should be addressed to Nancy G. Guerra, Department of Psychology, University of Illinois, 1007 West Harrison Street, M/C 285, Chicago, Illinois 60607. within these specific populations. Many studies have shown that early aggressive behavior is the best single predictor of risk for later aggression and delinquency (Farrington, 1991; Huesmann, Eron, Lefkowitz, \& Walder, 1984; Magnusson, Duner, \& Zetterblom, 1975; Olweus, 1979). The risk for serious childhood aggression, in turn, varies as a function of numerous individual and contextual factors. In the United States at this time, children growing up in economically disadvantaged urban communities represent a population with elevated risk for developing aggressive and violent behavior. In urban areas, rates of violence are highest among ethnic-minority youths living in the most disadvantaged inner-city neighborhoods, with crime rates as high as 300 per 100,000 (Fingerhut \& Kleinman, 1990; Hammond \& Yung, 1991; Shakoor \& Chalmers, 1991).

Indeed, there is a compelling need to develop effective preventive interventions in this setting. Unfortunately, there is a dearth of successful programs (for a review, see Guerra, in press). In part, the lack of effective strategies is related to the lack of attention to the etiology of aggression and violence within this context. Much of the child development research focused on the prediction of serious aggressive and antisocial behavior has been conducted with children growing up in largely White, middle-class communities, and very few studies have been concerned specifically with low-income urban minority children; yet, because the living conditions in disadvantaged urban communities are harsher than in most middle-class settings, specific information about aggression and risk within this environment is needed. 
Although inner-city communities are characterized by a multitude of chronic and persistent negative conditions as described by Wilson (1987), most explanations of the elevated risk in this setting have focused on the effects of economic disadvantage. In general, when samples include substantial representation of lower-class individuals, significant relations have been found between poverty and aggression among children (Patterson, Kupersmidt, \& Vaden, 1990) and adolescents (Spencer, Dobbs, \& Phillips, 1988). However, the standard methodology has been to compare "poor" with all other socioeconomic status levels, using individual indicators of income, socioeconomic status, or both. Not only does this preclude consideration of the differential effects of individual versus community poverty, it also obscures the effects of differing levels of economic disadvantage within the lower income groups. When mixed-ethnic samples are included, economic status and ethnicity are almost always confounded, and ethnic-minority participants who are poor are often compared with those who are not ethnic minorities or poor.

If poverty increases risk of aggressive behavior, this relation should be strongest in the poorest communities, where lack of individual resources is compounded by lack of community services. For instance, limited access to resources such as health care and nutrition may increase the likelihood that children are born with individual vulnerabilities that place them at greater risk for aggression (Bronfenbrenner, Moen, \& Garbarino, 1984). In a resource-poor environment, a relatively mild individual impairment might also escalate into a more serious disorder, evoking a chain of failed person-environment encounters (Lorion, Tolan, \& Wahler, 1987; Sameroff \& Chandler, 1975). Consider a minor learning disorder that, if left uncorrected, might intensify into more serious academic difficulties and problematic relationships, increasing the child's risk for later aggressive and violent behavior.

Still, it is debatable whether lack of economic resources can explain all or even most of the elevated violence currently found in inner-city communities. Throughout history, different groups of people have experienced substandard living conditions and extreme poverty without a parallel escalation in violence. For example, Tagaki and Platt (1978) studied Chinese immigrants living in San Francisco's Chinatown during the 1960s. They found that violent crime rates were extremely low in spite of the fact that Chinatown residents had the lowest income, highest unemployment rate, least educational attainment, and highest proportion of substandard housing in any area of the city. This is also the case for individuals in specific jobs who experience temporary or persistent poverty. As Jencks (1992) notes, "if low incomes alone drove people to crime, graduate students and clergymen would also commit a lot of crimes" (p. 113).

Rather than poverty per se, factors that are associated with poverty for certain people at certain times may increase risk for aggression. These factors are correlated with poverty, but they are not equivalents. This leads to an important but unresolved issue regarding the processes by which the inner-city environment might contribute to risk across gender and ethnicity. The extant literature reveals two factors that may be influential: stressful events and beliefs promoting aggression.

Individuals living in inner-city communities are exposed to a relentless succession of stressful events in the context of chronically stressful conditions. Stress exposure increases risk for a range of socioemotional and behavioral problems (Compas, Howell, Phares, Williams, \& Giunta, 1989; Pryor-Brown \& Cohen, 1989; Rutter, 1983), and the effects of stress exposure are multiplicative rather than additive (Garmezy, 1987). Still, few studies of the stress-adjustment relation have focused on disadvantaged urban children who are exposed to multiple stressors, and even fewer studies have examined the effects of different types of stressors on aggressive behavior. We know little about the effects of neighborhood violence, although such exposure should relate to individual aggression (Bandura, 1986).

Growing up in disadvantaged urban settings may also encourage individual beliefs promoting aggression (Miller, 1958). For example, both the research literature and the popular press frequently depict a pervasive sense of hopelessness shared by many inner-city residents (Kotlowitz, 1991). When expectations for success through conventional channels are low, individuals who believe that life is "hopeless" may turn to more aggressive means of obtaining immediate rewards. In addition, through observation and direct tuition, children may also adopt normative beliefs approving of aggressive behavior as a means of gaining status, material rewards, or simply coping with fear of victimization (Guerra, Huesmann, \& Hanish, 1994). Anderson (1990) reports that a "code of violence" often prevails among youths in impoverished urban areas whereby violence is seen as a legitimate and appropriate behavior in numerous social interactions. Empirical support for a relation between aggressive behavior and normative beliefs approving of aggression has been reported in samples of urban children (Huesmann, Guerra, Miller, \& Zelli, 1992), although the relation between economic status and beliefs was not evaluated.

In the present study, using two waves of data collected from a large sample of children, we investigated the joint influence on aggression of (a) individual and community poverty, (b) stressful events (negative life events and exposure to violence), and (c) individual beliefs (hopelessness and beliefs approving of aggression). Although the ecology of the inner-city environment is extremely complex and affects children at multiple levels, these factors have been implicated in previous studies and should be particularly relevant to preventive interventions.

\section{Method}

\section{Participants}

Participants for this study were the initial cohorts of a large-scale assessment and intervention study conducted in lower income neighborhoods of one large and one mid-size midwestern city. All participants were selected through a school recruitment process that was based on the school's willingness to participate in all phases of this study. This recruitment process involved an extensive application and screening process, which differed slightly across sites.

In the large-city site, applications were sent to 130 elementary schools in the public school system that satisfied the criteria of (a) $25 \%$ or more of the student population from low-income families and (b) $50 \%$ of the student population from minority families. From this original group, 52 schools with enrollments of less than 800 students (the maximum feasible for our research procedures) returned applications. Presentations to faculty were made and were followed up by presentations to the parent-teacher governing body at each school. Each principal in these 
schools then polled the faculty, and 13 schools reported $100 \%$ support from the faculty. From these schools, four were selected with the largest percentage of low-income African American children and four were selected that had the largest proportion of low-income Hispanic (predominantly Mexican American) children.

In the midsized city, recruitment was slightly different for the east and west school districts. In the east district, project personnel met with the superintendent and the principals from all 14 elementary schools. Of these schools, 13 invited personnel to present the study to the faculty. The final selection of the four east district schools was identical to procedures used in the large city. In the west district, project personnel met with members of the school board to identify appropriate schools. The same procedure involving applications and presentations was followed, and four schools were selected with our standard criteria. Because schools in the midsized city were integrated, four schools were selected with the highest percentage of African Americans and four schools were selected with the highest percentage of Hispanic (predominantly Mexican American ) children.

Parents permission was solicited for all children in these schools. Using a multistep procedure, we were able to obtain an overall permission rate of $86.6 \%$. In two of the schools, the permission rate was relatively low (average below $67.5 \%$ ), and these schools were replaced by two new schools from a waiting list. The permission rate in these new schools was equivalent to the other 14 , and they were retained. Of the children who received permission within these 16 schools, all who had been on the first-, second-, and fourth-grade class lists in the spring of 1991 and were on the second-, third-, and fifth-grade class lists in the fall of 1992 $(N=1,935)$ were selected as participants for the study. The sample was $45 \%$ African American, 36\% Hispanic, and 18\% White; 33\% first graders, $32 \%$ second graders, and $35 \%$ fourth graders; and $49 \%$ boys and $51 \%$ girls.

\section{Assessment Procedures and Attrition}

Three sources of data were used. The 1,935 children and their peers were assessed in their classrooms; archival data about the economic status of 1,211 of the children were collected from the schools; and more detailed economic information was obtained about a subsample of 461 children from short interviews with parents.

Two waves of classroom assessments on the 1,935 children were conducted. Wave 1 data were obtained from a schoolwide assessment conducted late in the 1990-1991 school year in the 14 original schools (when the children were finishing the first, second, or fourth grades) and early in the 1991-1992 school year in the two replacement schools (when the children were starting the second, third, or fifth grades, respectively). The children were assessed with peer-nomination measures, teacher ratings, and self-report questionnaires. Wave 2 data were collected late in the 1992-1993 school year when all of the children were finishing the third, fourth, or sixth grades respectively. In Wave 2, the children were reassessed on the same peer-nomination and self-report measures. The measures were administered individually for children in the first grade in Wave 1 and were administered in the child's regular school classroom for children in the remaining grades. In all cases, the experimenter read the questions aloud for each measure. In classrooms with Spanish-speaking children, measures that had been translated according to standard procedures were provided, and children were permitted to choose the language of testing. At least one Spanish-speaking experimenter was present.

Over the 2 years between the first wave of data collection in the spring and fall of 1991 and the second wave of data collection in the spring of $1993,490(25 \%)$ of the 1,935 children moved or transferred to another school not in the study. In addition, 202 children were lost when their school refused to participate further in the study leaving an available sample of 1,243 children. Although the $25 \%$ attrition rate is high, it is representative of the normal school attrition rates in these neighborhoods for 2 years. As is typical for studies of aggression, the participants present for both waves of assessments scored lower on aggression than the 692 participants who dropped out after Wave $1,(M=.211$ vs. $M=$ $.234), t(1919)=2.70, p<.007 .^{1}$

In addition to assessing the 1,935 participants in school, we collected information from school records on as many of the children as possible. Archival data from the schools were collected during the 1991-1992 school year. Because of incomplete record keeping by the schools, we were unable to locate information on free-lunch status for 724 children, leaving a sample of 1,211 with such data. As one might expect, the 724 whose lunch data could not be located scored higher on initial peernominated aggression $(M=.233)$ than the others $(M=.211), t(1919)$ $=2.63, p<.009$.

During the fall of the 1991-1992 school year, an attempt was made to collect information from parents. Various methods were used, including phone contacts, mail contacts, and individual contacts at times when parents came to school for report card pick-up. Unfortunately, in these urban schools, only $40 \%$ of families had listed telephone numbers, and parental attendance at report-card meetings was low. Nevertheless, we obtained some information on family socioeconomic indicators from the parents of 461 children. As expected, the children of the parents who were not interviewed scored higher on initial aggression $(M=$ .228 vs. $M=.189$ ) than the children whose parents were interviewed, $t(1919)=4.10, p<.001$.

The fact that several of the subsamples examined in this study are somewhat less aggressive than the total initial sample may result in a restriction of range of aggression. This, in turn, may attenuate the magnitude of the relations between aggressive behavior and other variables, but it is unlikely to lead to any Type I errors.

\section{Measures}

Aggressive behavior. The Peer-Nominated Index of Aggression (Eron, Walder, \& Lefkowitz, 1972) was used to obtain a measure of each child's aggression. The methodology employed to obtain peernominated scores for a child has been used for over 30 years with demonstrated reliability and validity in several countries (Huesmann \& Eron, 1986). In this procedure, each child is presented with a printed page with a list of all boys and girls in his or her classroom, with the names grouped by gender. The child is asked to circle every name that fits the question at the top of the page (e.g., "Who pushes and shoves other children?"). The experimenter paces the children so that exactly the same amount of time is spent on each question. A child's score on a scale is derived by taking the number of times the child is nominated by all other children on questions that fall on that scale and dividing by the total number of times the child could have been nominated. These peer nomination scores range from 0 to 1 .

The teachers also rated all permission children on the teacher version of the Child Behavior Checklist (CBCL; Achenbach, 1978, 1991). This reliable and well-validated measure contains a list of 118 behavior problem items which the teacher rates on a 3-point scale. For the purposes of the current study, only the 39-item aggression scale of the checklist is important. Scores were computed for each child on the basis of the most recent norms for 6 to 11 year old children (Achenbach, 1991).

Individual and community economic status. Individual economic status data were obtained through the school archives for most children and were supplemented by information from a parent questionnaire for the subsample whose parents could be interviewed. According to the official school records, children were designated as belonging to one of

\footnotetext{
' Initial peer-nominated aggression data were not available on $14 \mathrm{chil}$ dren in Wave 1 leaving a sample size of 1,921 for analyses of Wave 1 peer-nominated aggression.
} 
three categories: (a) no free lunch, (b) partial free lunch, (c) and free lunch. The maximum allowable family income for free lunch is slightly above the official poverty level. In the parent questionnaire, parents provided information on occupation of primary and secondary income earner, years of education of both earners, and number of months the primary income earner was employed during the past year. Because of the narrow range of occupations, only years of education and number of months primary income earner was employed were used.

We were also interested in assessing the economic status of the communities in which the participants' schools were located. We used the average free lunch rate for each school as our measure of community poverty. The percentage of students receiving free or reduced lunch in each school ranged from $25 \%$ to $82 \%$. To further validate the free lunch categorization as a measure of the economic status of the communities where schools were located, we obtained 1990 census tract data for the census tracts served by each school. According to these data schools with between $25 \%$ and $50 \%$ free lunch rates were in neighborhoods with median family incomes ranging from $\$ 24,000$ to $\$ 27,000$. Approximately $6 \%$ of the residents in these neighborhoods received public aid, and housing typically consisted of rental apartments and condominiums. The schools with more than $50 \%$ of the students receiving free lunch were located in neighborhoods with median family incomes ranging from $\$ 8,900$ to $\$ 17,000$, with an average of $44 \%$ of families receiving public aid, and with housing consisting of rental apartments and highrise and low-rise public housing developments.

Stressful events. To measure stressful events, the Stress Index, a 16item self-report scale (Attar, Guerra, \& Tolan, 1994) was used. This scale was derived from a longer stress scale that had been used in several previous studies of antisocial behavior risk (Tolan, Miller, \& Thomas, 1988). Ten of the items on the scale measured stress caused by negative life events such as a family member becoming seriously ill or the child being placed in foster care, and the remaining six items measured stress due to neighborhood violence. Children completed the index by indicating whether they had experienced each of the stressful events during the past year.

Beliefs. Two types of beliefs were measured: hopelessness and approval of aggression. To measure hopelessness, we used the Hopelessness Scale for Children (Kazdin, French, Unis, Esveldt-Dawson, \& Sherick, 1983). The scale contains 17 items and uses a true-false response format. Although the direction of responding is reversed for eight of the items, the scale is scored so that a higher score indicates greater hopelessness or negative expectancies for the future. A sample item is "all 1 can see ahead of me are bad things, not good things." In the current population of children, coefficient alpha for the 17 -item scale was found to be .45 for younger children and .62 for older children.

The Normative Beliefs About Aggression Scale (NOBAGS) is a 20item scale used to assess individual's beliefs about the acceptability of aggressive responses (Guerra et al., in press; Huesmann \& Guerra, 1994). Eight items tap general beliefs about aggression (e.g., "in general, it's OK to use violence"), and the remaining 12 items tap specific retaliation beliefs about the acceptability of aggression under particular circumstances (e.g., "it's OK for a girl to hit a boy if the boy says something bad first"). Children respond on a 4-point scale with higher scores indicating more support for aggression. The items tapping specific retaliation beliefs were derived by varying four key dimensions ( severity of provocation, severity of response, gender of provoker, and gender of victim). The scale was developed with several samples of inner-city elementary school children. In the present sample, coefficient alpha for the full scale is .85, and the subscales all have reliabilities above .70.

\section{Results}

The results of this study are presented in four major sections. First, we examine how aggression is distributed within this popula- tion across gender and age. Second, we examine how aggression, economic status, and ethnicity covary. Third, we assess the synchronous relations between aggression, economic status, stressful events, and individual beliefs. Finally, we examine how these correlates contribute to changes in aggression over time.

\section{Levels of Aggressive Behavior}

The aggression scores in this sample were quite high by national standards for children this age. The mean score for all boys and girls was $.219(S D=.178)$ on peer-nominated aggression. This indicates that, on average, children were nominated $21.9 \%$ of the times they could have been nominated on the aggression items. By contrast, in their study of a semirural low- to middle-income population in 1960, Eron, Walder, \& Lefkowitz (1972) found that, on average, children were nominated $11.9 \%$ of the time. The overall mean score on the CBCL for all children was $6.56(S D=10.1)$, which falls at about the 70th percentile on national norms (Achenbach, 1991). Approximately 20\% of the entire sample scored above 16 , which would be about the 90 th percentile on national norms.

As expected, the distribution of aggression scores on both peer nominations and the CBCL were skewed. The skewness was greater for CBCL scores ( skewness $=1.27$ for peer-nominations and 1.57 for CBCL scores). The two aggression measures are also very highly correlated $(r=.63, p<.001)$, especially when one considers the limitations that their skewed distributions place on a correlation coefficient. The lower skewness of the peer nomination measure makes it a better variable for parametric analysis and suggests that it discriminates better among low range and mid-range values of aggression. As a result, peer-nominated aggression is the criterion variable in most analyses.

The mean scores on peer-nominated aggression are plotted as a function of gender and grade in Figure 1. As expected, an analysis of variance revealed a significant Gender $\times$ Grade interac-

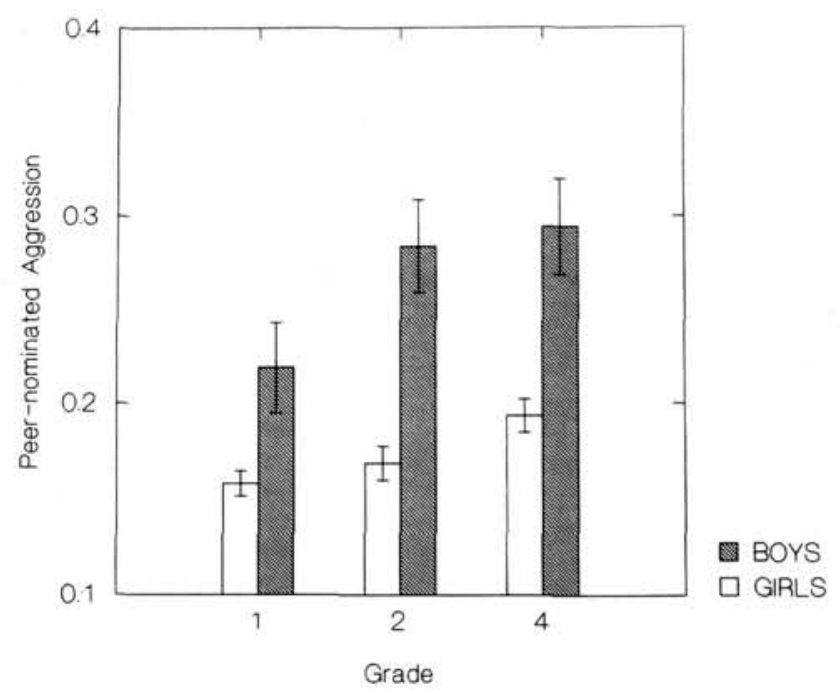

Figure 1. Mean peer-nominated aggression scores as a function of gender and grade. 


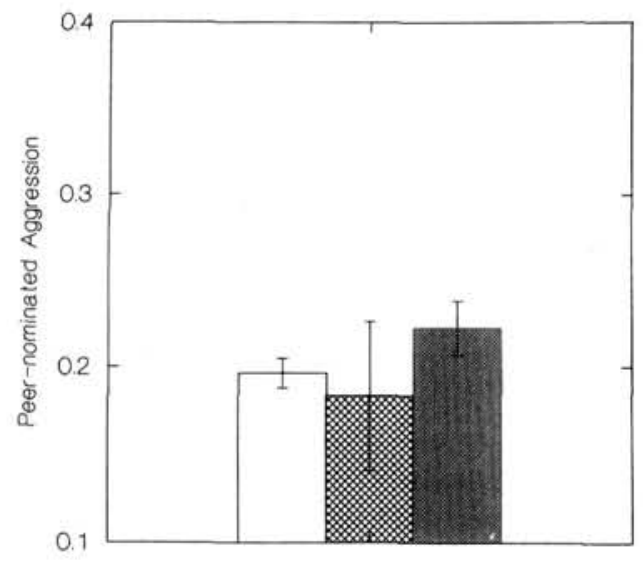

Free Lunch Status

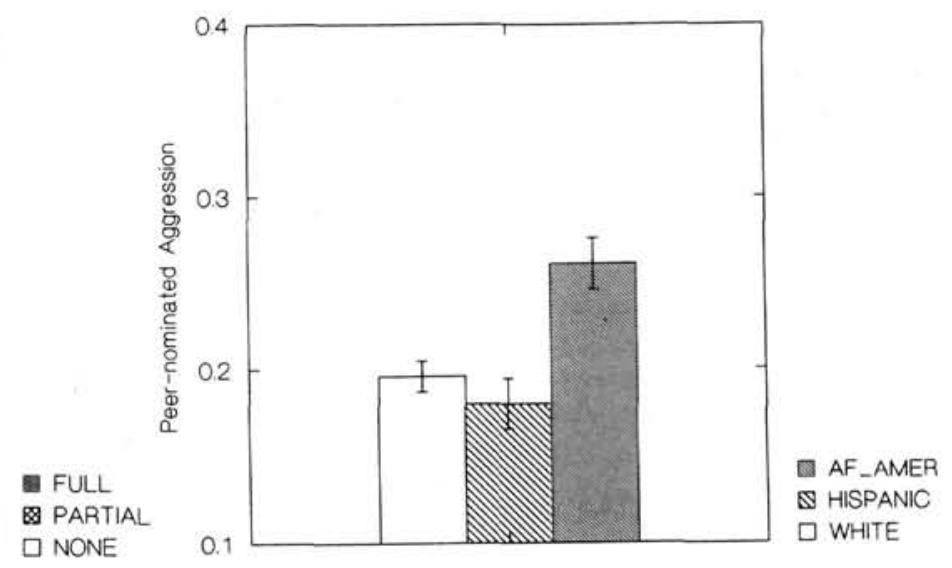

Ethnic Group

Figure 2. Mean peer-nominated aggression scores as a function of free-lunch status and ethnicity. AF$\mathrm{AMER}=$ African American.

tion, $F(2,1915)=4.30, p<.014$, a main effect for gender with boys more aggressive, $F(1,1915)=141.3, p<.001$, a main effect for grade with older children more aggressive, $F(2,1921)$ $=18.1, p<.001$. As Figure 1 reveals, the Gender $\times$ Grade interaction is caused by boys increasing more in aggression from first to second grade than girls. These effects for gender and grade were present within all three ethnic groups.

\section{Aggression, Economic Status, and Ethnicity}

In Figure 2, peer-nominated aggression is plotted for the three different levels of individual free lunch status and for the three ethnic groups. As seen, the poorest children display significantly more aggression, $F(2,1202)=5.517, p<.004$. African American children also display significantly more aggression than the other groups, $F(2,1898)=51.8, p<.0001$. As Figure 3 displays, free lunch status also varies significantly across ethnic groups, $\chi^{2}(4, N=1211)=226.6, p<.0001$, with African American children having the highest proportion qualifying for free lunch.
Taken together, these figures illustrate a fundamental confounding in this population that makes it very difficult to separate the effects of poverty from other factors related to ethnicity. As a result, we conducted subsequent analyses within ethnic groups as well as across groups.

\section{Synchronous Relations Among Aggression, Economic Status, Stressful Events, and Individual Beliefs}

In Table 1 the correlations for all participants are shown between aggressive behavior, the economic status variables, and the stressors and individual beliefs variables. As Table 1 shows, aggression correlates weakly but significantly with individual free lunch, consistent with the data presented in Figure 2. The data in Table 1 from the parent subsample show that parents who have been employed more during the last year have less aggressive children, although the education of the parents by itself does not predict aggression.

However, the strongest correlate of aggressive behavior in Table 1 is a child's normative beliefs in the appropriateness of ag-

Table 1

Correlations Between Aggressive Behavior, Economic Status, Stressful Events, and Individual Beliefs $(N=1,921)$

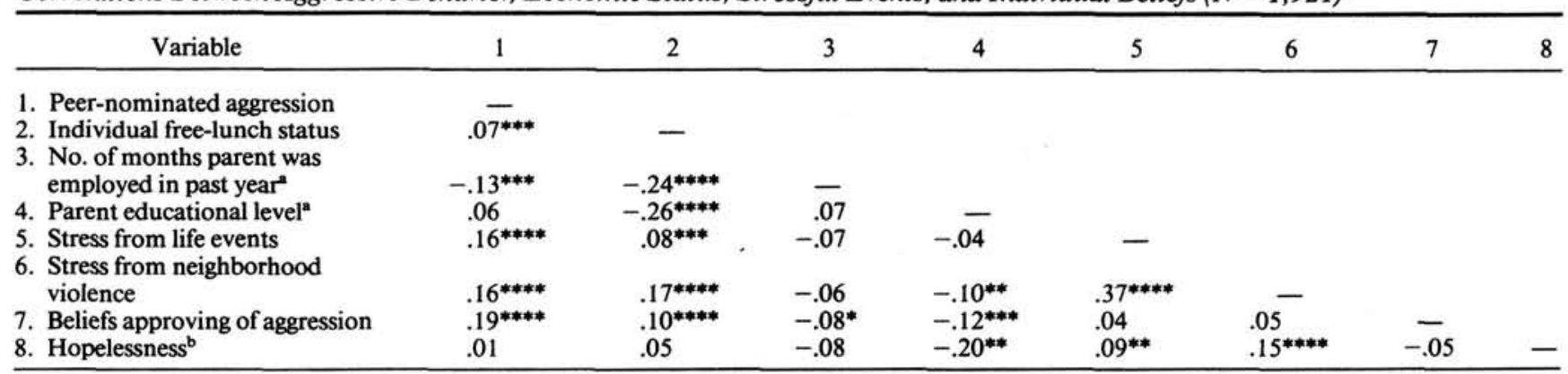

a $n=461$ from parent interview data. ${ }^{\mathrm{b}} n=609$.

${ }^{* *} p<.025$ (one-tailed). ${ }^{* * *} p<.01$ (one-tailed). ${ }^{* * * *} p<.001$ (one-tailed). 


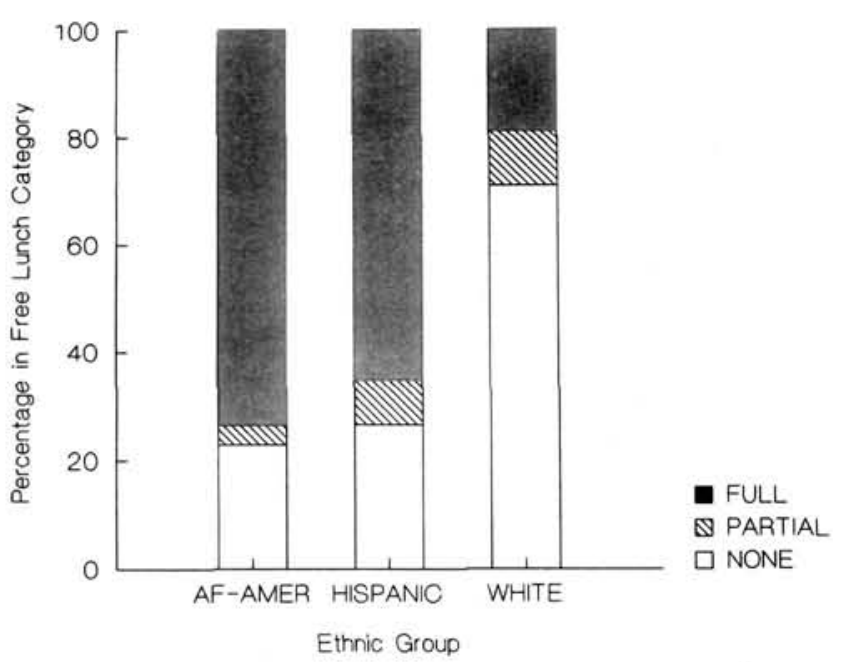

Figure 3. Percentage of children from each ethnic group who are in each free-lunch category. AF-AMER = African American.

gression. These beliefs also correlate with free-lunch status. On the average, poorer children have beliefs that are more accepting of aggressive behavior, and children with these beliefs behave more aggressively. Similarly, the two stress measures correlate significantly with aggression and relate significantly to freelunch status. More impoverished children experience more neighborhood violence stress and more life-event-related stress, and those children who experienced more stress engage in more aggressive behavior.

Contrary to expectation, individual differences in children's "hopelessness" as measured by Kazdin et al.'s (1983) scale were not related at all to aggression or economic status per se. However, children's hopelessness was related inversely to the parent's education and directly to the amount of stress in their lives. As hopelessness did not relate at all to aggression, it was dropped from subsequent analyses.

The correlations were also computed for male and female participants, and there was little change. Next, we re-examined the correlations of these variables separately for each ethnic group. As Table 2 illustrates, the positive correlation between peer-nominated aggressive behavior and self-reported beliefs approving of aggression was highly significant in all three ethnic groups. The correlations between more aggressive behavior and exposure to life events stress and neighborhood violence stress also held up across ethnic groups. However, individual free lunch status only correlated with aggression for the White children. There was substantial variation in economic status in the other two samples, but that variation did not relate to more or less aggressive behavior.

To estimate more accurately the separate contributions to aggressive behavior of the several correlates of poverty that we have measured, we calculated a series of multiple regressions predicting aggressive behavior. To have a consistent sample in these cross-sectional and longitudinal analyses, we used the sample of 866 children for whom archival data on free-lunch status, complete Wave 1 data, and complete Wave 2 data were available. As one might expect, the children included in these analyses were less aggressive in Wave 1 than the excluded children $(M=.209$ vs. $M=.228), t(1919)=2.38, p<.02$, and lived in communities with lower average school free lunch status $(45.3 \%$ vs. $48.3 \%, p<.01)$.

In Table 3, hierarchical multiple regressions are presented (for all participants and separately for male and female participants) relating children's aggressive behavior to individual and average school free-lunch status, stressful events, and normative beliefs, with grade as a covariate. The first regression for each sample includes only the effects of grade and individual free-lunch status. This regression shows that, for all children and for boys and girls separately, poorer children behave more aggressively independently of grade. The effects are not large but are significant. The second regression for each sample shows what happens when average school free-lunch status, stressful events, and children's normative beliefs about aggression are added to the prediction. The most notable finding is that for the total sample, both life-events stress and neighborhood violence stress are the best predictors of aggression, with aggressive nor-

Table 2

Correlations Between Aggressive Behavior, Economic Status, Stressful Events, and Individual Beliefs by Ethnic Group

\begin{tabular}{|c|c|c|c|c|c|c|}
\hline \multirow[b]{2}{*}{ Variable } & \multicolumn{2}{|c|}{$\begin{array}{l}\text { White } \\
(n=356)\end{array}$} & \multicolumn{2}{|c|}{$\begin{array}{l}\text { Hispanic } \\
(n=708)\end{array}$} & \multicolumn{2}{|c|}{$\begin{array}{l}\text { African American } \\
\quad(n=857)\end{array}$} \\
\hline & $\begin{array}{l}\text { Peer-nominated } \\
\text { aggression }\end{array}$ & $\begin{array}{l}\text { Individual } \\
\text { free-lunch } \\
\text { status }\end{array}$ & $\begin{array}{l}\text { Peer-nominated } \\
\text { aggression }\end{array}$ & $\begin{array}{l}\text { Individual } \\
\text { free-lunch } \\
\text { status }\end{array}$ & $\begin{array}{l}\text { Peer-nominated } \\
\text { aggression }\end{array}$ & $\begin{array}{l}\text { Individual } \\
\text { free-lunch } \\
\text { status }\end{array}$ \\
\hline Peer-nominated aggression & 1.00 & & 1.00 & & 1.00 & \\
\hline Individual free-lunch status & $.15^{* * *}$ & 1.00 & -.01 & 1.00 & .03 & 1.00 \\
\hline No. of months parent was employed & & & & & & \\
\hline in past year" & -.07 & $-.41^{* * * *}$ & -.05 & -.08 & -.08 & $-.36^{* * * *}$ \\
\hline Educational level ${ }^{*}$ & -.11 & -.07 & .08 & $-.17^{* * * *}$ & -.04 & -.17 \\
\hline Stress from life events & $.11^{*}$ & .10 & $.10^{* *}$ & $.10^{*}$ & $.13^{* * *}$ & .08 \\
\hline Stress from neighborhood violence & $.23^{* * * *}$ & .08 & $.08^{* *}$ & .05 & $.11^{* *}$ & $.13^{* * * *}$ \\
\hline Beliefs approving of aggression & $.19^{* * * *}$ & .07 & $.20^{* * * * *}$ & $.09^{*}$ & $.15^{* * * *}$ & .04 \\
\hline
\end{tabular}

"For these measures from parent interview data, $n=123$ for White, $n=226$ for Hispanic, and $n=109$ for African American participants.

${ }^{*} p<.05$ (one-tailed). ${ }^{* *} p<.025$ (one-tailed). ${ }^{* * *} p<.01$ (one-tailed). ${ }^{* * * *} p<.001$ (one-tailed). 
Table 3

Standardized Regression Coefficients Predicting Peer-Nominated Aggression From Free-Lunch Status and Correlates of Economic Disadvantage

\begin{tabular}{|c|c|c|c|c|c|c|}
\hline \multirow[b]{2}{*}{ Predictor variable, $R^{2}$, and $d f \mathrm{~s}$} & \multicolumn{2}{|c|}{$\begin{array}{l}\text { All participants } \\
(n=866)\end{array}$} & \multicolumn{2}{|c|}{$\begin{array}{c}\text { Male } \\
(n=440)\end{array}$} & \multicolumn{2}{|c|}{$\begin{array}{c}\text { Female } \\
(n=426)\end{array}$} \\
\hline & Regres 1 & Regres 2 & Regres 1 & Regres 2 & Regres 1 & Regres 2 \\
\hline Grade & $.14^{* * * * *}$ & $.13^{* * * *}$ & $.11^{* * * *}$ & $.08^{*}$ & $.18^{* * * *}$ & $.23^{* * * * *}$ \\
\hline Individual & $.11^{* * * * *}$ & .07 & $.08 *$ & $.13^{*}$ & $.13^{* * *}$ & -.02 \\
\hline Average school & & .01 & & .11 & & -.18 \\
\hline Individual $\times$ Average School & & .01 & & -.21 & & $.31^{* *}$ \\
\hline Stress from life events & & $.08^{* *}$ & & $.13^{* * *}$ & & $.09^{*}$ \\
\hline Stress from neighborhood violence & & $.14^{* * * * *}$ & & $.12^{* * *}$ & & $.18^{* * * * *}$ \\
\hline Beliefs approving of aggression & & $.10^{* * *}$ & & $.11 * *$ & & -.02 \\
\hline$R^{2}$ & $.027^{* * * *}$ & $.072^{* * * *}$ & $.018^{* * *}$ & $.076^{* * * *}$ & $.046^{* * * *}$ & $.118^{* * * *}$ \\
\hline$d f \mathrm{~s}$ & 2,863 & 7,858 & 2,437 & 7,432 & 2,423 & 7,418 \\
\hline
\end{tabular}

Note. Complete data cases only. Regres = regression; Individual = individual free-lunch status; Average School $=$ average school free-lunch status.

${ }^{*} p<.05$ (one-tailed). ${ }^{* *} p<.025$ (one-tailed). ${ }^{* * *} p<.01$ (one-tailed). ${ }^{* * * *} p<.001$ (one-tailed).

mative beliefs also significant. Individual free-lunch status becomes nonsignificant as a predictor of aggression, suggesting that the relation between poverty and aggression is partially due to associated stressful events and beliefs supporting aggression.

The separate regressions in Table 3 for boys and girls confirm the role of stress for both genders. However, normative beliefs rival stress as a predictor only for boys. For boys, individual free lunch status remains a significant predictor of aggression in conjunction with these other variables, and for girls the combination of individual and average school free lunch status predicts significantly. Apparently, there are some factors related to economic status, besides normative beliefs and stress, that predict individual differences in aggression within genders but not across genders.

Regression analyses in the subsample of 461 participants on whom we collected parent interviews suggested that these re- sults are not dependent on the choice of the free-lunch variable as a marker of economic status. After individual free-lunch status was entered as a predictor, neither parents' employment status nor education added significantly to the prediction of aggression. With all three in the equation, the best predictors of aggression in this subsample were still the two stress variables $(p<.004$ and $p<.005)$, followed by the normative beliefs measure $(p<.07)$.

These regressions were recomputed separately for the three ethnic subgroups ( see Table 4). Consistent with the correlations displayed earlier in Table 2, individual free-lunch status only has a significant relation to children's aggression in the White subgroup. However, when all the variables are added into the equation, neighborhood violence stress had a significant effect on aggression in all subgroups. In addition, aggressive normative beliefs is a significant predictor for the Hispanic children.

Table 4

Standardized Regression Coefficients Predicting Peer-Nominated Aggression From Free-Lunch Status and Correlates of Economic Disadvantage for Ethnic Subgroups

\begin{tabular}{|c|c|c|c|c|c|c|}
\hline \multirow[b]{2}{*}{ Predictor variable, $R^{2}$, and $d f \mathrm{~s}$} & \multicolumn{2}{|c|}{$\begin{array}{c}\text { White } \\
(n=168)\end{array}$} & \multicolumn{2}{|c|}{$\begin{array}{l}\text { Hispanic } \\
(n=383)\end{array}$} & \multicolumn{2}{|c|}{$\begin{array}{l}\text { African American } \\
\quad(n=315)\end{array}$} \\
\hline & Regres 1 & Regres 2 & Regres 1 & Regres 2 & Regres 1 & Regres 2 \\
\hline $\begin{array}{l}\text { Grade } \\
\text { Individual } \\
\text { Average school } \\
\text { Individual } \times \text { Average School } \\
\text { Stress from life events } \\
\text { Stress from neighborhood violence } \\
\text { Beliefs approving of aggression }\end{array}$ & $\begin{array}{l}.10 \\
.26^{* * * * *}\end{array}$ & $\begin{array}{l}.12 \\
.29^{* * * * *} \\
.36^{* *} \\
-.30^{*} \\
.03 \\
.26^{* * * * *} \\
.07\end{array}$ & $\begin{array}{l}.08 \\
.01\end{array}$ & $\begin{array}{l}.06 \\
.02 \\
-.02 \\
-.08 \\
.03 \\
.13^{* *} \\
.13^{* * *}\end{array}$ & $\begin{array}{l}.21^{* * * *} \\
.07\end{array}$ & $\begin{array}{l}.22^{* * * * *} \\
-.08 \\
-.43^{* * * *} \\
.39^{* *} \\
.09 \\
.10^{*} \\
.06\end{array}$ \\
\hline$R^{2} d f \mathrm{~s}$ & $\begin{array}{c}.073^{* * *} \\
2,165\end{array}$ & $\begin{array}{l}.171^{* * * * *} \\
7,160\end{array}$ & $\begin{array}{r}.006 \\
2,380\end{array}$ & $\begin{array}{l}.053^{* * *} \\
7,375\end{array}$ & $\begin{array}{c}.046^{* * *} \\
2,312\end{array}$ & $\begin{array}{l}.094^{* * * * *} \\
7,307\end{array}$ \\
\hline
\end{tabular}

Note. Complete data cases only. Regres = regression; Individual = individual free-lunch status; Average School $=$ average school free-lunch status.

${ }^{*} p<.05$ (one-tailed). ${ }^{* *} p<.025$ (one-tailed). ${ }^{* * *} p<.01$ (one-tailed). ${ }^{* * * *} p<.001$ (one-tailed). 


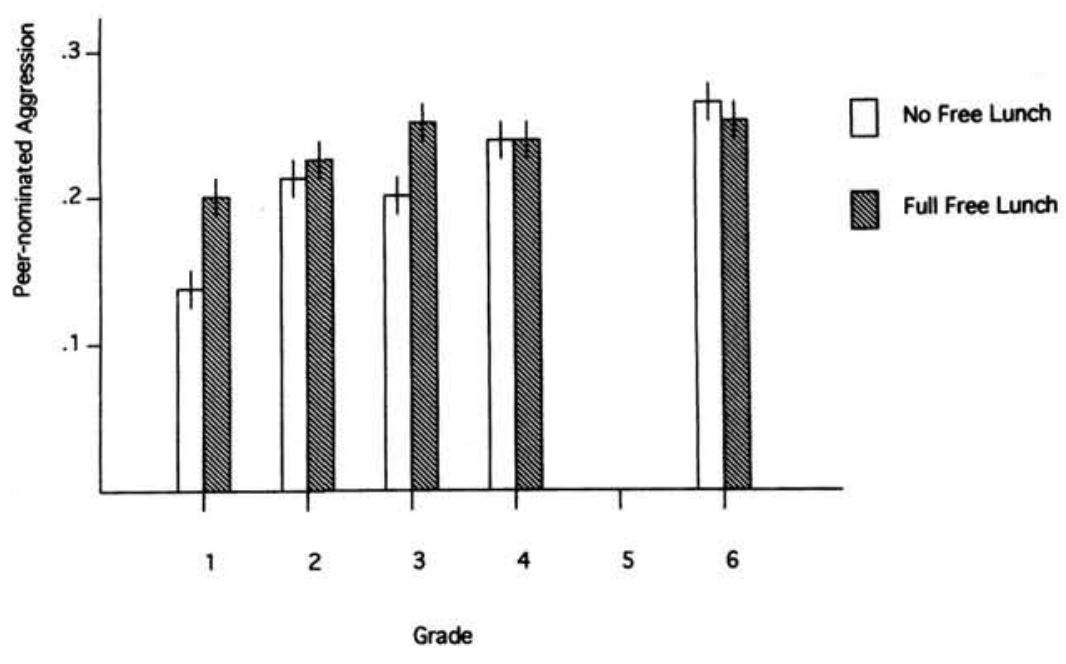

Figure 4. Mean peer-nominated aggression as a function of free-lunch status and grade.

The coefficients for school free-lunch status and the combination of school and individual status are significantly negative for Whites and significantly positive for African Americans.

\section{Longitudinal Predictions of Aggression}

The aforementioned analyses have examined the relations among aggression, economic status, stressful events, and beliefs about aggression synchronously at one time point. Although it is unlikely that economic status changes much over short periods of time in this context, aggressive behavior does vary significantly over time during childhood. A better understanding of the contributions of these variables to aggression and their importance in prevention can be obtained from an examination of how well they predict changes in aggression over time.

We first examined how the relation between individual economic status and aggression changes with age (see Figure 4). Although there are large differences in aggression related to free lunch for young children, these differences seem to disappear among older elementary school children. These results suggest that the most important effects of low economic status on children occur at early ages. It may be that low economic status increases stress and stimulates beliefs in support of aggression in young children. These factors lead to the development of aggressive habits that become relatively stable over time, so at older ages the direct relation between low economic status and aggression is diminished.

To evaluate such a possibility, we tested a linear structural model in which individual economic status was hypothesized to predict early stressful events, beliefs, and aggression which, in turn, were hypothesized to predict later aggression. We evaluated the model using a maximum likelihood estimation procedure, and the results are shown in Figure 5 for all participants and for each ethnic subgroup. The measurement parameters for stress and beliefs were fixed across all four samples on the basis of an initial measurement evaluation, but the other parameters were all estimated separately within each sample. The model fits the observed pattern of correlations well within the total sample and within each subgroup. The chi-square test indicates that the model reproduces the correlations within the bound- aries of expected error, and the root-mean-square errors are relatively small.

These results suggest that low economic status exerts its effects on young children's aggression to a great extent through the stressful events and normative beliefs associated with low economic status. Once aggressive habits are formed, they tend to predict future aggressive habits, but stress and beliefs still may have independent effects on later aggression for some children. For African American and White children the effects of poverty on beliefs was much less significant than for Hispanic children. Also, for Hispanic children the effects of stress and beliefs on later aggression were stronger than for African American or White children. Of course, these models do not preclude the possibility that low economic status may affect aggression through other mediators as well and that other factors unrelated to economic status may influence beliefs and stress.

\section{Discussion}

There were three major findings. First, both teacher reports and peer nominations demonstrated that inner-city elementary school children display relatively high average levels of aggressive behavior as compared to less disadvantaged samples (e.g., Achenbach, 1991; Eron et al., 1972). Aggression increases strikingly at the beginning of these children's school careers, suggesting that the school environment in itself may be promoting aggression, particularly for boys. Second, our results suggest that within this disadvantaged environment, African Americans experience the greatest economic disadvantage, and that such disadvantage is associated with higher aggression scores early in development. It is difficult to unconfound this relation, and it suggests that great caution is required in interpreting data relating economic status, ethnicity, and aggression. Third, taken together, the cross-sectional and longitudinal analyses suggest that the effects of individual economic status are largely explained by the effects of stressful events and beliefs about aggression. Poorer children are more likely to experience greater life events stress and neighborhood violence stress. Poorer children are also more likely to adopt beliefs accepting of aggres- 

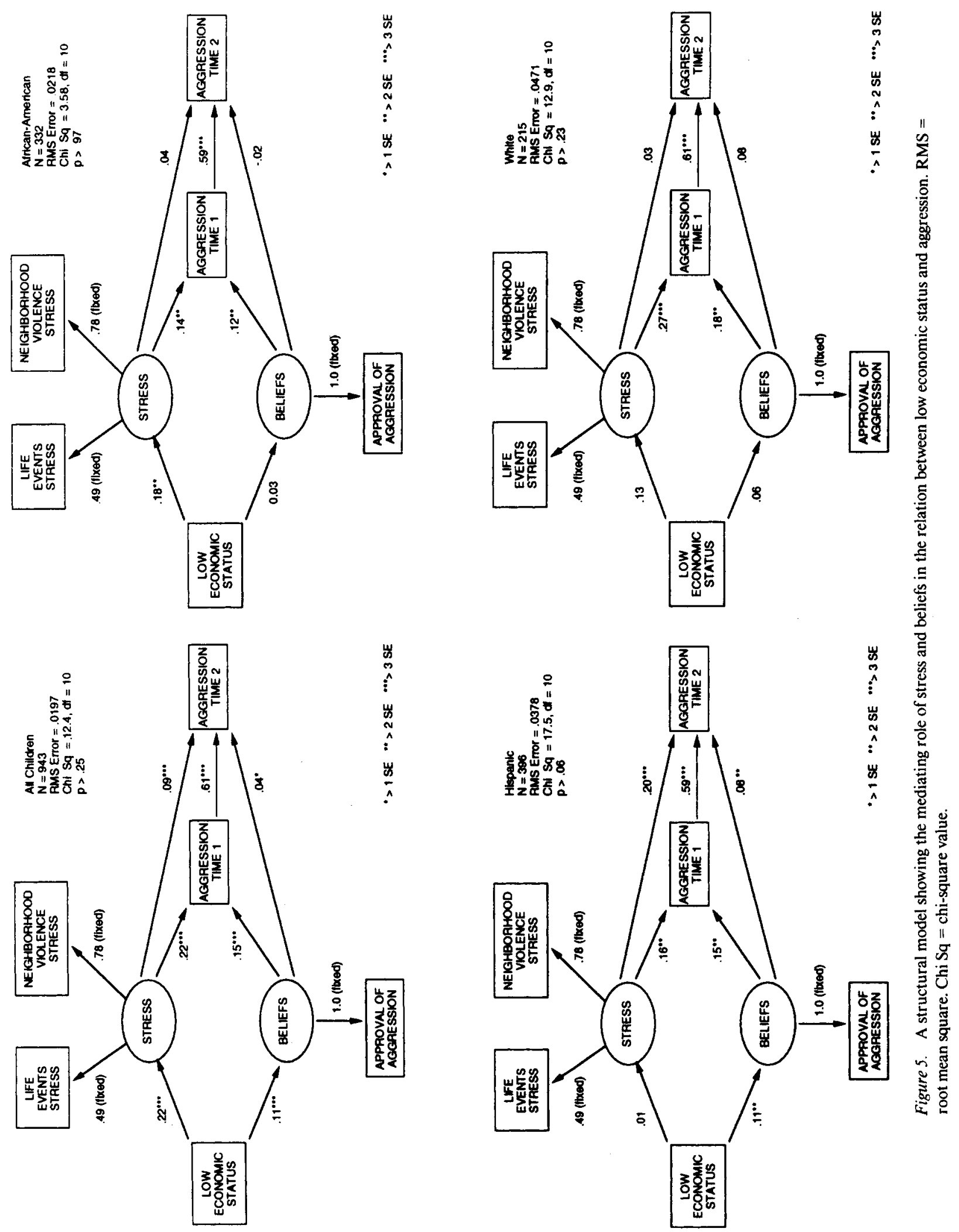
sion. These beliefs and stressors predict early aggression that, in turn, predicts aggression in subsequent years.

Our results suggest that preventive interventions are particularly appropriate for children from families of low economic status in these low-income communities. When we examined the results for individual and community economic status, we found that individual but not community status was a weak but significant direct predictor of aggression overall. However, when we examined this relation by age, it was only significant in the early elementary grades; that is, within an economically disadvantaged sample with a limited range of income, younger children from the poorest families display higher rates of aggression. The effects of individual poverty seem to dissipate by the later elementary years, although caution should be exercised in interpreting this finding because of higher attrition among the lower economic status and high-aggression children.

Economic status is clearly confounded with ethnicity and both are related to aggression. When we examined the relation between economic status and aggression separately for each ethnic group, this direct relation between individual economic status and aggression was not evident among Hispanic or African American children. However, community economic status did interact with individual status to relate to aggression for Whites and African Americans, but a clear interpretation of those interactions is difficult. It may be that poorer White children in the more disadvantaged communities behave more aggressively, whereas poorer African American children in less disadvantaged communities are more aggressive. In any case, a clear implication of this finding is that ethnicity appears to be an important moderator of this relation, highlighting the need to examine proposed mechanisms of influence separately for different ethnic groups and develop interventions that are sensitive to cultural differences in the etiology of aggression.

As our results demonstrated, for all ethnic groups the effects of low economic status appear to be mediated by both stressful events and individual beliefs. In the cross-sectional analyses, the correlation and regression analyses showed that life events stress, neighborhood violence stress, and beliefs approving of aggression were related to low economic status but predicted aggression in the total population better than did low economic status. The longitudinal analyses confirmed the importance of stress and beliefs in mediating the relation between poverty and aggression and in predicting aggression. Interestingly, for African American and White children, stress seemed to be the more important mediator, whereas for Hispanic children, beliefs seemed to be the more important mediator.

Given the relations among stress and poverty and among stress and aggression, these findings suggest that antiviolence interventions should (a) attempt to reduce the stressful events associated with poverty, (b) facilitate the acquisition of adaptive coping strategies, or (c) both. An example of a system-level intervention to reduce the stressors associated with poverty might be providing adequate tenant-owned low-income housing to reduce families' need to move frequently. Psychological efforts such as individual or family-level interventions might include an emphasis on adaptive skills for coping with events associated with urban poverty. In addition, skill-based programs must also address the role of individual beliefs about the appropriateness of specific behaviors including aggression. In settings where in- dividuals come to see aggression as legitimate and even desirable, preventive interventions must attempt to change these normative beliefs if acquired skills and behaviors are to be used.

These findings imply that preventive interventions for innercity children should target both individual and contextual factors if they are to work well. If community violence remains high, then neighborhood violence stress will remain high. If community violence is reduced but a particular boy does not change his views about aggression, then his beliefs are still likely to stimulate aggressive behavior. Programs that target both stressful events and normative beliefs approving of aggression are likely to have the greatest effects according to this study. Of course, one way to reduce the impact of stress on children is by teaching better coping skills and by providing better support. Finally, the differential results across ethnic groups and genders suggests that different preventive strategies may be more appropriate for different subgroups in economically disadvantaged environments.

\section{References}

Achenbach, T. M. (1978). The child behavior profile: I. Boys aged 611. Journal of Consulting and Clinical Psychology, 46, 478-488.

Achenbach, T. M. (1991). Integrative guide for the 1991 CBCL/4-18, $Y S R$, and TRF profiles. Burlington, VT: Department of Psychiatry, University of Vermont.

Anderson, E. J. (1990). Streetwise: Race, class, and change in an urban community. Chicago: University of Chicago Press.

Attar, B., Guerra, N. G., \& Tolan, P. H. (1994). Neighborhood disadvantage, stressful life events, and adjustment in urban elementary school children. Journal of Clinical Child Psychology, 23, 394-400.

Bandura, A. (1986). Social foundations of thought and action: A socialcognitive theory. Englewood Cliffs, NJ: Prentice-Hall.

Bronfenbrenner, U., Moen, P., \& Garbarino, J. (1984). Child, family, and community. In R. Parke (Ed.), Review of child development research: Vol. 7. The family (pp. 283-328). Chicago, IL: University of Chicago Press.

Compas, B. E., Howell, D. C., Phares, V., Williams, R. A., \& Giunta, C. T. (1989). Risk factors for emotional/behavioral problems in young adolescents: A prospective analysis of adolescent and parental stress and symptoms. Journal of Consulting and Clinical Psychology, 57, 732-740.

Eron, L. D., Walder, L. O., \& Lefkowitz, M. M. (1972). The learning of aggression in children. Boston: Little Brown.

Farrington, D. P. (1991) Childhood aggression and adult violence: Early precursors and later-life outcomes. In D. J. Pepler \& K. H. Rubin (Eds.), The development of childhood aggression (pp. 5-29). Hillsdale, NJ: Erlbaum.

Fingerhut, L. A., \& Kleinman, J. D. (1990). International and interstate comparisons of homicide among young males. Journal of the American Medical Association, 263, 3292-3295.

Garbarino, J., Kostelny, K., \& Dubrow, N. (1991). What children can tell us about living in danger. American Psychologist, 46, 376-382.

Garmezy, N. (1987). Stress, competence, and development: Continuities in the study of schizophrenic adults, children vulnerable to psychopathology, and the search for stress-resistant children. American Journal of Orthopsychiatry, 57, 159-174.

Guerra, N. G. (in press). Intervening to prevent childhood aggression in the inner-city. In J. McCord (Ed.), Growing up violent: Contributions of inner-city life. Cambridge University Press.

Guerra, N. G., Huesmann, L. R., \& Hanish, L. (1994). The role of normative beliefs in children's social behavior. In N. Eisenberg (Ed.), Social development (pp. 140-158). Thousand Oaks, CA: Sage. 
Guerra, N. G., \& Slaby, R. G. (1990). Cognitive mediators of aggression in adolescent offenders: II. Intervention. Developmental Psychology, 26, 269-277.

Guerra, N. G., Tolan, P. H., \& Hammond, W. R. (1994). Prevention and treatment of adolescent violence. In L. D. Eron, J. H. Gentry, \& P. Schlegel (Eds.), Reason to hope: A psychosocial perspective on violence and youth (pp. 383-403). Washington, DC: American Psychological Association.

Hammond, W. R., \& Yung, B. R. (1991). Preventing violence in at-risk African-American youth. Journal of Health Care for the Poor and Underserved. 2, 1-16.

Huesmann, L. R., \& Eron, L. D. (Eds.). (1986). Television and the aggressive child: A cross-national comparison. Hillsdale, NJ: Erlbaum.

Huesmann, L. R., Eron, L. D., Lefkowitz, M. M., \& Walder, L. O. (1984). Stability of aggression over time and generations. Developmental Psychology, 20, 1120-1134.

Huesmann, L. R., \& Guerra, N. G. (1994). Children's normative beliefs about aggression and aggressive behavior. Manuscript submitted for publication.

Huesmann, L. R., Guerra, N. G., Miller, L., \& Zelli, A. (1992). The role of social norms in the development of aggression. In H. Zumckly \& A. Fraczek (Eds.), Socialization and aggression. (pp. 139-151). New York: Springer-Verlag.

Jencks, C. (1992). Rethinking social policy. Cambridge, MA: Harvard University Press.

Kazdin, A. E. (1987). Treatment of antisocial behavior in children: Current status and future directions. Psychological Bulletin, 102, 187-203.

Kazdin, A. E. (1994). Interventions for aggressive and antisocial children. In L. D. Eron, J. H. Gentry, \& P. Schlegel (Eds.), Reason to hope: A psychosocial perspective on violence and youth (pp. $341-$ 382). Washington, DC: American Psychological Association.

Kazdin, A. E., French, N. H., Unis, A. S., Esveldt-Dawson, K., \& Sherick, R. B. (1983). Hopelessness, depression, and suicidal intent among psychiatrically disturbed inpatient children. Journal of Consulting and Clinical Psychology, 51, 504-510.

Kotlowitz, A. (1991). There are no children here. New York: Doubleday.

Lorion, R. P., Tolan, P. H., \& Wahler, R. G. (1987). Prevention. In $\mathrm{H}$. C. Quay (Ed.), The handbook of juvenile delinquency (pp. 417450). New York: Wiley.

Magnusson, D., Duner, A., \& Zetterblom, G. (1975). Adjustment: A longitudinal study. Stockholm, Sweden: Almqvist \& Wiksell.

Miller, W. (1958). Lower class culture as a generating milieu of gang delinquency. Journal of Social Issues, 14, 5-19.
Olweus, D. (1979). The stability of aggressive reaction patterns in human males: A review. Psychological Bulletin, 85, 852-875.

Patterson, C. J., Kupersmidt, J. B., \& Vaden, N. A. (1990). Income level, gender, ethnicity, and household compositions as predictors of children's school-based competence. Child Development, 61, 485494.

Pryor-Brown, L., \& Cowen, E. L. (1989). Stressful life events, support, and children's school adjustment. Journal of Clinical Child Psychology, 18, 214-220.

Rutter, M. (1983). Stress, coping, and development: Some issues and some questions. In N. Garmezy \& M. Rutter (Eds.), Stress, coping, and development in children (pp. 1-42). New York: McGraw-Hill.

Sameroff, A., \& Chandler, M. (1975). Reproductive risk and the continuum of caretaking casualty. In F. Horowitz, M. Hetherington, S. Scarr-Salapatek, \& G. Seigel (Eds.), Review of child development research (pp. 187-244). Chicago, IL: University of Chicago Press.

Shakoor, B., \& Chalmers, D. (1991). Co-victimization of AfricanAmerican children who witness violence: Effects on cognitive, emotional, and behavioral development. Journal of the National Medical Association, 83, 233-237.

Spencer, M. B., Dobbs, B., \& Phillips, D. (1988). African-American adolescents: Adaptational processes and socioeconomic diversity in behavioral outcomes. Journal of Adolescence, 11, 117-137.

Tagaki, P., \& Platt, T. (1978). Behind the gilded ghetto: An analysis of race, class and crime in Chinatown. Crime and Social Justice, 9, 225.

Tolan, P., \& Guerra, N. G. (in press). Prevention of juvenile delinquency. Journal of Applied and Preventive Psychology.

Tolan, P. H., Miller, L., \& Thomas, P. J. ( 1988). Perceptions and experience of types of social stress and self-image among adolescents. Journal of Youth and Adolescence, 17, 147-163.

Uniform Crime Reports. (1992). Washington, DC: Federal Bureau of Investigation.

Wilson, W. J. (1987). The truly disadvantaged. Chicago, IL: University of Chicago Press.

Yoshikawa, H. (1994). Prevention as cumulative protection: Effects of early family support and education on chronic delinquency and its risks. Psychological Bulletin, 115, 28-54.

Zigler, E., Taussig, C., \& Black, K. (1992). Early childhood intervention: A promising preventative for juvenile delinquency. American Psychologist, 47, 997-1006.

Received March 15, 1994

Revision received September 2, 1994 Accepted December 14, 1994 